\title{
O MUNDO QUE EU INVENTO, O MUNDO QUE ME INVENTA: VESTÍGIOS DE UM SELF PERDIDO
}

\author{
Maristela Provedel de Carvalho
}

\begin{abstract}
O trabalho enfoca a relação entre o mundo particular do indivíduo e o mundo externo. A ideia de um self perdido é usada como uma imagem representativa do que se passa na contemporaneidade, quando as pessoas se esforçam para ser uma unidade nas gigantescas comunidades "pós-modernas". Entrelaçando narrativas pessoais com pontuações advindas da psicanálise e das ciências sociais, descreve-se um perfil de pessoas que conseguem transitar pelos excessos utilizando um filtro especial que lhes permite preservar sua autenticidade.
\end{abstract}

\section{BANCA:}

Maria Inês Garcia de Freitas Bittencourt (Orientadora)

Alexandre Abranches Jordão

Flavia Sollero de Campos

Data de defesa: 10/12/2009 